\section{Recurrent rectosigmoid volvulus and fatal peritoni- tis after percutaneous endoscopic sigmoidostomy}

An 83-year-old woman with severe dilated cardiomyopathy and recurrent sigmoid volvulus ( Fig. 1) who was resident in a nursing home refused to undergo surgery and instead decided to undergo formation of a percutaneous endoscopic colostomy. A colonoscopy was performed as far as the cecum after oral preparation, so that the left colon was detorsioned. At $22 \mathrm{~cm}$ from the anal verge, which was the first part of the sigmoid colon that could be transilluminated, a standard 22-Fr percutaneous endoscopic gastrostomy (PEG) tube (Compat Nuport, Novartis, Basel,

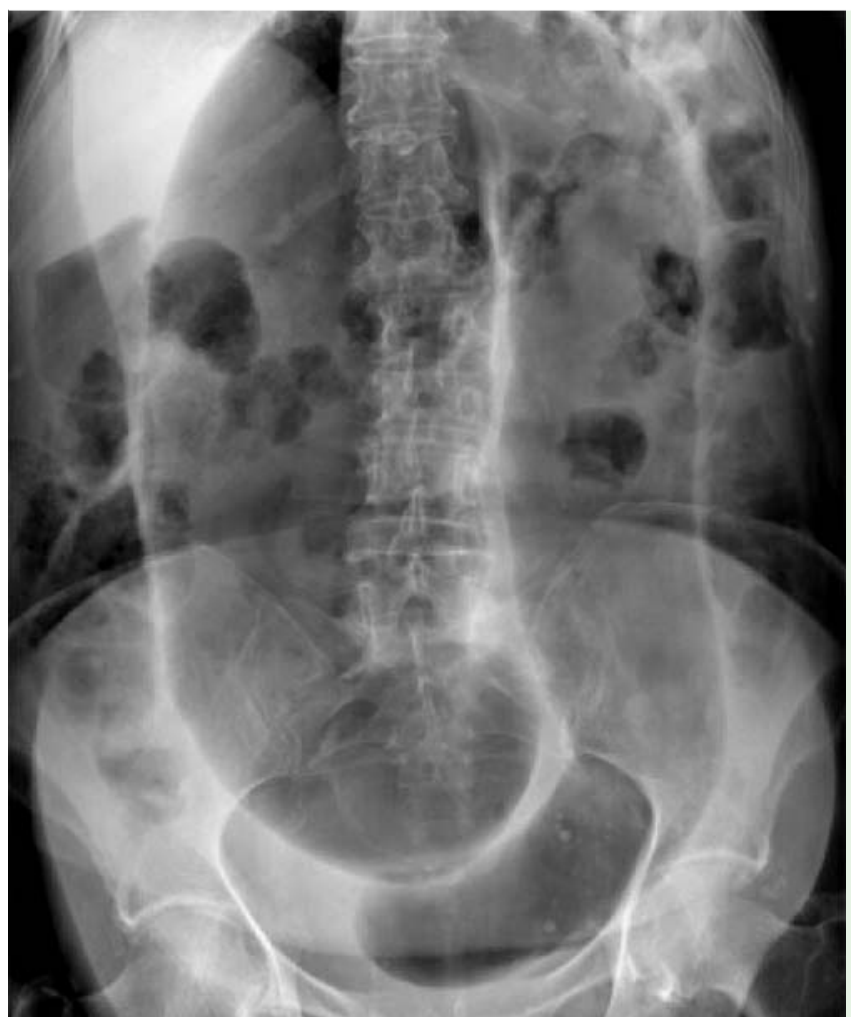

Fig. 1 Abdominal radiograph in an 83year-old woman showing the classical "coffee bean" sign of a sigmoid volvulus.
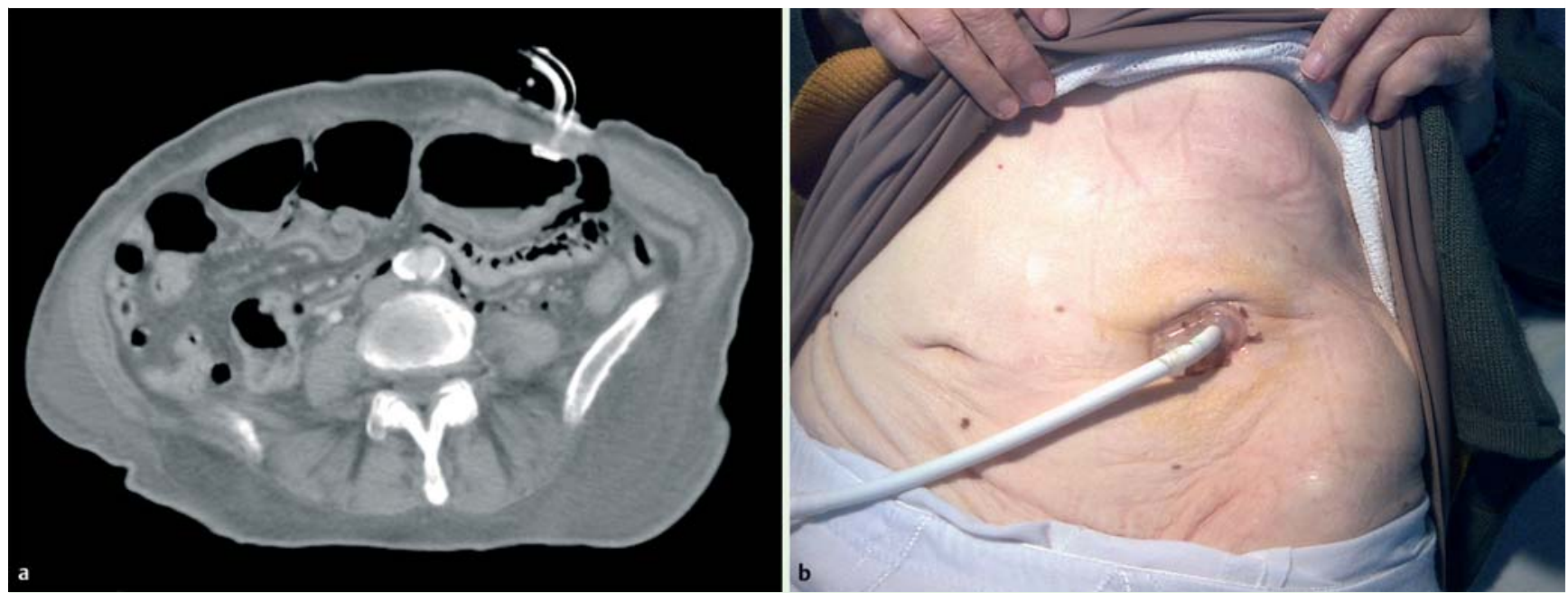

Fig. 3 a Abdominal computed tomography (CT) scan showing the colostomy tube 1 month after percutaneous endoscopic insertion. $\mathbf{b}$ Photograph of the colostomy tube exiting through the abdominal wall following percutaneous endoscopic insertion. 


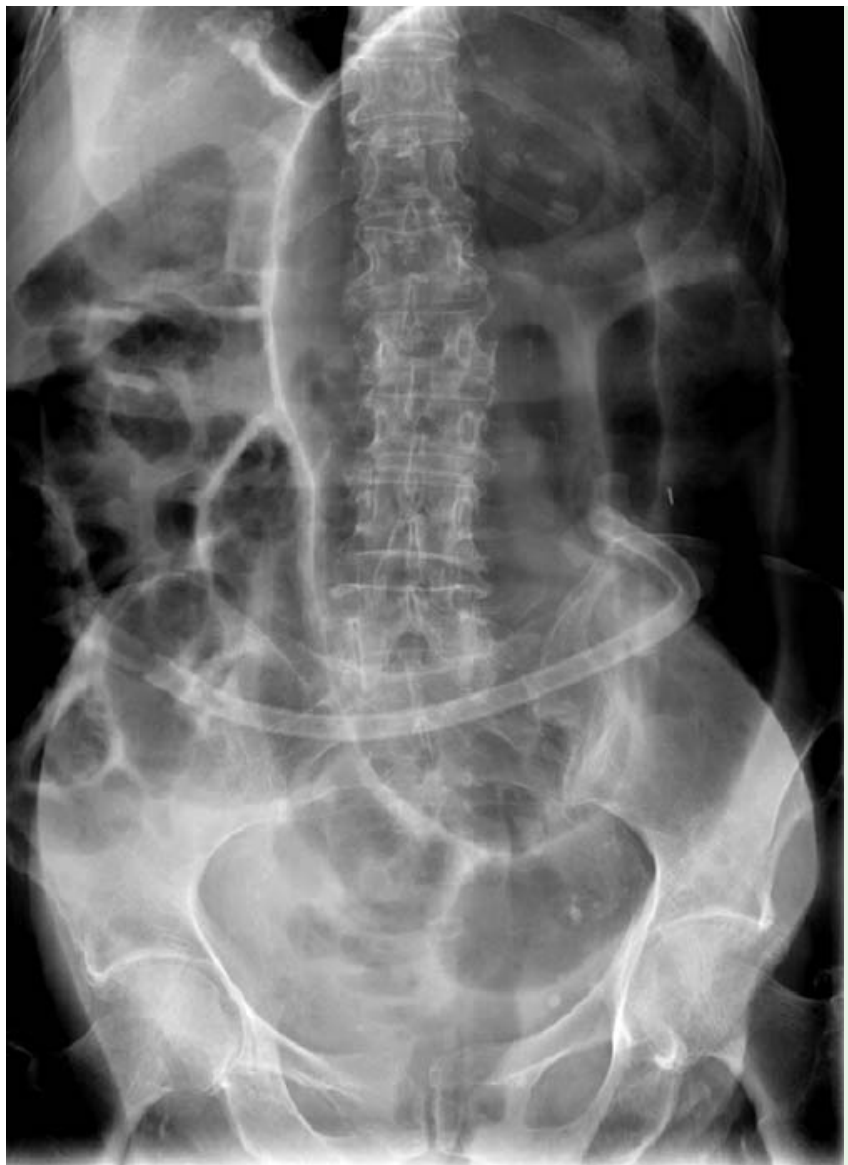

Fig. 4 Abdominal radiograph taken on re-admission 7 weeks later showing a recurrent lower gastrointestinal volvulus $7-8 \mathrm{~cm}$ below the sigmoid fixation.

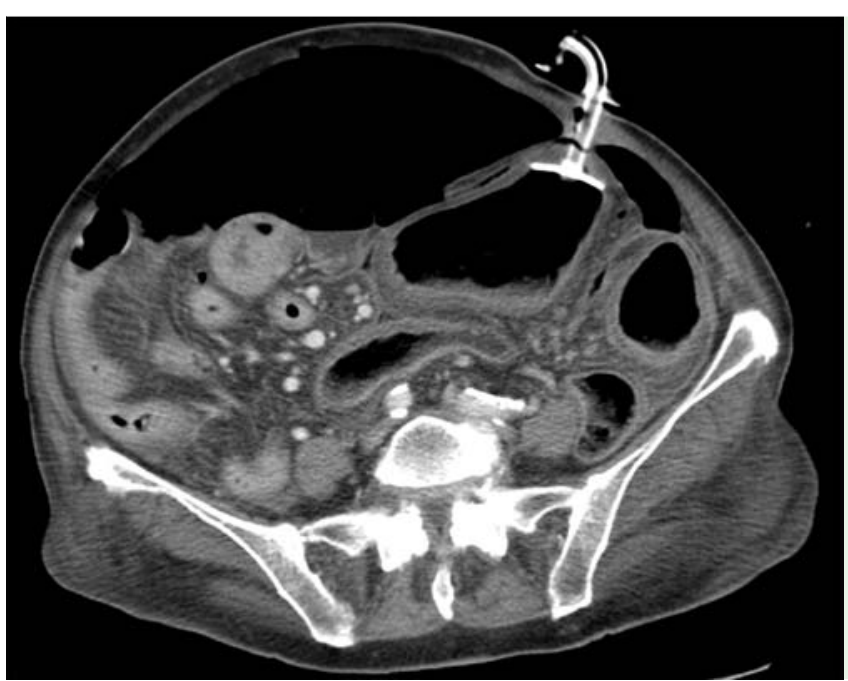

Fig. 5 Abdominal computed tomography (CT) scan revealing a massive pneumoperitoneum and the internal bumper of the colostomy no longer affixed to the abdominal wall.

moid colon with formation of an end colostomy was performed, but unfortunately the patient died 24 hours later from cardiopulmonary failure.

A definitive therapy for recurrent sigmoid volvulus in high risk surgical patients is yet to be determined. Lately percutaneous fatal peritonitis has been reported to be a serious delayed complication [5] because a colocutaneous fistula may take longer to mature than a PEG owing to the fragility of the colonic wall and its bacterial contents. This case emphasizes the need for proper post-procedural care of patients following this procedure.

Endoscopy_UCTN_Code_CPL_1AJ_2AI

Competing interests: None

\section{J. Molina-Infante, M. Fernandez- Bermejo, J. M. Mateos-Rodriguez}

Department of Gastroenterology, Hospital San Pedro de Alcantara, Caceres, Spain

\section{References}

1 Cowlam S, Watson C, Elltringham $M$ et al. Percutaneous endoscopic colostomy of the left side of the colon. Gastrointest Endosc 2007; 65: 1007-1014

2 Baraza W, Brown S, McAlindon M et al. Prospective analysis of percutaneous endoscopic colostomy at a tertiary referral centre. Br J Surg 2007; 94: 1415-1420

3 Mullen R, Church NI, Yalamarthi S. Volvulus of the sigmoid colon treated by percutaneous endoscopic colostomy. Surg Laparosc Endosc Percutan Tech 2009; 19: e64-e66

4 Al-Alawi IK. Percutaneous endoscopic colostomy: A new technique for the treatment of recurrent sigmoid volvulus. Saudi J Gastroenterol 2010; 16: 120-121

5 Bertolini D, De Saussure P, Chilcott $M$ et al. Severe delayed complication after percutaneous endoscopic colostomy for chronic intestinal pseudo-obstruction: a case report and review of the literature. World J Gastroenterol 2007; 13: 2255-2257

\section{Bibliography}

Dol http://dx.doi.org/

10.1055/s-0032-1309858

Endoscopy 2012; 44: E331-E332

(c) Georg Thieme Verlag KG

Stuttgart · New York

ISSN 0013-726X

\section{Corresponding author}

\section{J. Molina-Infante, MD}

Unit of Gastroenterology

Hospital San Pedro de Alcantara

C/ Pablo Naranjo s/n

10001 Caceres

Spain

Fax: +34-927-621545

xavi_molina@hotmail.com 